\title{
No-humanos, tiempos-espacios y socialidad amazónica entre los llanchama runa del río Tiputini* $^{*}$
}

\author{
Ignacio Andrés Contreras Ilabaca \\ (iD) https://orcid.org/0000-0002-7881-6830 \\ Facultad Latinoamericana de Ciencias Sociales (FLACSO) - Ecuador \\ ignacio.cilabaca@gmail.com
}

RESUMEN

Proponemos un análisis de las relaciones con la alteridad que los seres no-humanos y la selva como entidad viviente establecen con los llanchama runa del río Tiputini en la Amazonia ecuatoriana. Para desarrollar esta propuesta recogemos tres relatos que nos fueron compartidos durante nuestro trabajo de campo y que narran encuentros vivenciales entre seres humanos y no-humanos, con especial atención en las nociones de tiempo y espacio en que acontecieron. Confrontamos nuestros datos con la teoría perspectivista y las ontologías relacionales para profundizar en los modos particulares con que los humanos enfrentan los cruces de perspectivas y en la figura del chaman como mediador y restaurador de la vida cotidiana cuando esta es perturbada por los intentos predatorios de las entidades no-humanas. Veremos que los llanchama runa tratan con las agencias no-humanas empleando valores especificos, relacionales y transformadores, movilizándose en dos tiempos-espacios diferenciados y simultáneos; condición que les permite seguir existiendo y habitando la selva bajo un modelo de socialidad siempre creativo y performativo de predadores y presas.

* Este trabajo se ha realizado en el marco de la investigación para la tesis de maestría en Antropología Visual en la Facultad Latinoamericana de Ciencias Sociales, sede en Ecuador, entre los años 2017 y 2019. 
Palabras clave: Amazonía, tiempo-espacio, humanos yno-humanos, chamanismo, alteridad.

\title{
Non-humans, time-spaces and Amazonian sociality among the Llan- chama Runa of the Tiputini River
}

\author{
ABSTRACT
}

We propose an analysis of the relationships with otherness that nonhumans and the forest as a living entity establish with the Llanchama Runa of the Tiputini River in the Ecuadorian Amazon. In order to develop this proposal, we have collected three stories that were shared with us during our fieldwork and that narrate experiential encounters between human and non-human beings, with special attention to the notions of time and space in which they occurred. We confront our data with the perspectivist theory and relational ontologies to delve into the particular ways in which humans face the crossings of perspective and into the figure of the shaman as a mediator and restorer of everyday life when it is disturbed by the predatory attempts of non-human entities. We will see that the Llanchama Runa deal with non-human agencies using specific, relational and transformative values, mobilising themselves in two differentiated and simultaneous times-spaces; a condition that allows them to continue to exist and inhabit the forest under the social model of predators and preys that is always creative and performative.

Keywords: Amazon, time-space, humans and non-humans, shamanism, otherness. 


\section{INTRODUCCIÓN}

Los kichwa que habitan en la Amazonia ecuatoriana se «identifican como runa, palabra que en quichua significa ser humano, y los del Napo como napo runa. Internamente, los napo runa se diferencian a sí mismos utilizando los nombres de los pueblos o la zona del río de donde provienen» (Muratorio, 1998, p. 18) ${ }^{1}$. La cuenca del río Napo, uno de los principales afluentes del río Amazonas, en particular el Alto Napo, fue una región de frontera y encuentros, de relaciones e intercambios materiales y simbólicos entre sociedades de las altas montañas andinas y sociedades de las tierras bajas orientales desde mucho antes que arribasen conquistadores y misioneros en el siglo XVI (Muratorio, 1998; Taylor, 1994). Esta zona era habitada por diferentes pueblos, entre ellos, Quijo, Omagua, Sápara, que en su contacto con las sociedades occidentales, primero coloniales y luego nacionales, vivieron sus procesos de construcción de mismidad/alteridad como runa en la cuenca del río Napo (Hudelson, 1987; Macdonald, 1997; Muratorio 1998, Oberem 1980; Uzendoski 2010, Whitten, 1987).

Las relaciones entre continuidades y cambios, entre reproducción y transformación, deben leerse «más allá de la pérdida y ganancia de ciertos rasgos culturales» (Magnoni, 2018, p. 98). En este sentido, y en concordancia con el antropólogo Michael Uzendoski, entendemos que «las identidades de los kichwa están definidas por valores relacionales y formas específicas en vez de estar determinadas por la idea abstracta o esencialista del ser runa» (Uzendoski, 2010, p. 38). Ellos se caracterizan por una vida social y ontología relacional, donde incorporan elementos de las otras sociedades con quienes conviven. Así, «el kichwa amazónico se puede percibir como un complejo de múltiples identidades teniendo a awallakta (de las tierras altas, refiriéndose a personas blancas

En este artículo usaré indistintamente los términos runa, llanchama runa, kichwa, para referirme a mis interlocutores en el campo según corresponda. 
y mestizos) y awka (salvaje) como extremos» (Uzendoski, 2010, p. 39). En estas intersecciones y cruces de perspectivas, los runa reinterpretaron y resignificaron algunos principios de la religión cristiana, hicieron del kichwa su lengua y se fueron asentando organizadamente como comunidades a lo largo del río Napo y sus afluentes.

Nuestro trabajo de campo e interlocución se desarrolló con una de estas, precisamente, con la comunidad kichwa de Llanchama, ubicada sobre el margen izquierdo del río Tiputini, aguas arriba desde su confluencia con el río Napo. Su territorio tiene una superficie aproximada de unas 26000 hectáreas y se encuentra en su totalidad tanto dentro del Parque Nacional Yasuní como sobre los bloques petroleros 31 y 43 gestionados por la estatal Petroamazonas. Administrativamente forma parte de la parroquia Tiputini, cantón de Aguarico, provincia Francisco de Orellana, en Ecuador. Desde el 12 julio del año 1978 viven en su actual territorio, luego de liberarse de los patrones y del trabajo en las haciendas caucherasagrícolas-ganaderas que caracterizaron las relaciones interétnicas entre los runa y los no-runa, en la frontera amazónica de Ecuador y Perú, entre finales del siglo XIX y la segunda mitad del siglo $\mathrm{XX}^{2}$.

De mucho tiempo los abuelos le habían puesto ese nombre. Llanchama es por el estero aquíarribita, ese decimos llanchama. Otro aquí arribita decimos yahuatiyaku. Entonces, que losviejos han puesto ese nombre, tratamos lo mismo nosotros. Y lagunas lo mismo. Todo han puesto nombre ellos, no podemos cambiar nosotros. Hay un árbol que se saca la corteza que se llamaba llanchama y entonces ahí le ponen el nombre de llanchama. Nuestros abuelos han puesto eso (Mario, en conversación con el autor, 9/5/2019).

2 Este periodo caracterizado por las haciendas y los patrones se conoce como cawchu uras (Whitten, 1987; Reeve, 1988, 1988a; Cabodevilla, 2007) que en lengua kichwa significa «tiempo del caucho»y en ella se albergan las vivencias de los runa que trabajaron en la recolección de la goma para los distintos señores caucheros en las selvas de Napo. En aquel entonces Ecuador, como su vecino Perú, países recientemente soberanos e independientes de la corona española, buscaron los medios para ocupar de manera efectiva la región amazónica de frontera e incorporarla a sus respectivos proyectos de Estado-Nación, siendo el comercio del caucho el principal vehículo para conseguirlo. Para ello se valieron de todo tipo de métodos en su ejecución. Este río de contacto y sus selvas fueron protagonista y testigo del ascenso del capitalismo industrial; sin embargo, este se sostuvo en relaciones sociales y económicas de tipos esclavistas y feudales. Solo con la llegada de las compañías petroleras, la reforma agraria y el arribo de la misión capuchina al vicariato de Aguarico en la ciudad del Coca, se inicia un cambio estructural en las relaciones sociales y económicas de producción de los runa del Napo, incorporándose al trabajo asalariado desde la segunda mitad del siglo XX en adelante. 
Mis ancestros han llegado en los años 1800, de los cuales ha sido ese el abuelo de mi abuela. Se llamaba Agustín Huatatoca, cual es los primeros que llegaron por este río para poder viviren la cabecera que le llamamos nostros Tivacuno. A la larga de lo que vivían nuestros ancestros llegaron los patrones. Entonces, a la larga vivían allá y salieron a hacer compras yluego retornaban. Y en eso nace mi abuelita Victoria Huatatoca en San Carlos, de la boca de Tiputini a dos kilómetros. Entonces, vuelta retornan a la misma zona, que es el río Tiputini. Hasta hoy en día nosotros seguimos viviendo en esta zona que es Llanchama, pero ellos más era que vivían en Tivacuno (Andrés, en conversación con el autor, 24/04/2019).

Permanecimos en el oriente ecuatoriano junto a la antropóloga Emily Carraro alrededor de veinte semanas, entre febrero y mayo de 2019. Durante este periodo nos movilizamos entre el poblado fronterizo de Nuevo Rocafuerte y la comunidad kichwa de Llanchama. Con estos, establecimos un acuerdo de colaboración donde se nos permitió estar en su territorio a cambio de recoger y sistematizar sus relatos sobre el origen e historia de la comunidad y la idea de devolver un producto audiovisual editado de las entrevistas realizadas, ya que para ellos era fundamental documentar su presencia en las selvas del Tiputini antes de la constitución del Parque Nacional Yasuní. Dialogamos y entrevistamos a los llanchama runa pertenecientes a distintos ayllu (en lengua kichwa se usa para referirse a la unidad familiar o grupo extendido de personas que mantienen lazos de parentesco y familiares entre sí). Para tal propósito, nos valimos del registro audiovisual de historias orales sobre el origen e historia de la comunidad.

De aquel material etnográfico hemos seleccionado para tratar aquí tres relatos que ocurrieron en el pasado o en el pasado reciente, y que narran encuentros de seres espirituales-animales de la selva con personas humanas. El primer relato corresponde al matrimonio mayor de Heriberto y Brígida, con quienes vivimos mientras estuvimos en Llanchama. Él nos cuenta sobre aquellos seres espirituales que viven en el interior de la selva, en sus respectivos mundos, y que vienen al mundo de los runa para atraerlos, robárselos y convertirlos en marido o mujer según sea el caso. Mientras que Brígida nos detalla su encuentro con uno de estos seres a orillas del río Napo, el Yaku Runa, espíritu que habita en los cuerpos de agua y con capacidad de metamorfosis y de comunicarse a través de los sueños. En el segundo relato, Cristian nos narra cuando pasó dos noches y tres días en el monte al perderse mientras se encontraba de cacería. Luego de caminar y caminar selva adentro, logró reorientarse y volver a la comunidad; sin embargo, por la noche no pudo dormir, ya que observaba y escuchaba animales dentro de su habitación. Por último, el tercer relato corresponde a Andrés, quien nos cuenta la historia de 
Pillán, tío de su abuela Victoria. Este relato oral es sabido y compartido por todos los ayllu de la comunidad. Trata sobre uno de sus antepasados, que fue seducido por un ser-mujer-espiritual de la selva y que habita actualmente en el interior de una laguna que lleva su nombre. Para los llanchama runa este siempre ha sido su territorio, donde han convivido junto a seres y entidades de múltiples naturalezas. Los no-humanos son vistos como sujetos con agencia con quienes deben tratar e interactuar para hacer posible su habitar. El concepto de agencia lo entendemos como la «capacidad creativa de actuar de forma transformadora sobre la realidad sociocultural» (Fausto y Heckenberger, 2007, p. 12), capacidad de la que, según los runa, disponen tanto ellos como las demás entidades de la selva.

\section{MODELO PREDATORIO E INCORPORACIÓN DE LA ALTERIDAD}

Las relaciones entre humanos y no-humanos que caracterizan a los pueblos de las tierras bajas sudamericanas nos conducen hacia una apertura ontológica que se encuentra inscrita en sus cosmologías y en las formas de habitar junto a los demás seres existentes y con/en el territorio (Tola, 2019). El denominado giro ontológico constituye un debate contemporáneo en la disciplina antropológica y ha sido teorizado desde los estudios amazónicos por enfoques tanto perspectivistas (Viveiros de Castro 1996; 2004; 2010) como animistas (Descola, 2004; 2012). La literatura nos muestra que según con quienes se fabriquen las relaciones de alteridad, estas se pueden agrupar en tres grandes campos: con seres animales y seres espirituales (Stolze Lima 1996; Viveiros de Castro, 2010; Descola; 2012), con elementos del paisaje, como bosques, ríos, montañas, cascadas, lagunas (Rival, 2004; Kohn, 2013), y un tercer grupo referido a objetos, cosas y artefactos (Santos Granero, 2012).

En cada uno de estos trabajos se reconoce que existe un universo ontológico plural que atañe a la composición del mundo material y simbólico de los pueblos amazónicos, donde quien percibe y conoce es la persona, condición que comparten tanto seres humanos como animales, plantas, elementos del paisajes, objetos y artefactos. En este sentido, se sitúa al «sujeto perceptivo en el centro de la reflexión antropológica, como paso ineluctable para comprender las teorías locales de la persona, de lo social y del cosmos» (Surrallés, 2002, p. 63). Desde estos postulados, la selva en sí misma puede ser comprendida, sentida y vivida como un ser más con quien se debe establecer una relación que permita a los humanos y no-humanos habitarla. Las relaciones con la alteridad constituyen el núcleo del universo cosmológico de las sociedades amazónicas. Sin embargo, 
vale decir que estas interacciones no son idénticas entre los seres «pensantes y sintientes» (Medrano y Tola, 2016, p. 105), ni tampoco son ilimitadas. Por lo contrario, se despliegan bajo ciertos modelos y dependerán siempre de las naturalezas ontológicas que se encuentren fabricando la relación.

Animismo, perspectivismo y multinaturalismo son conceptos antropológicos que surgen del diálogo entre las y los antropólogos y sus corresponsales en el campo amazónico. No son conceptos propiamente nativos o vernaculares, sino más bien elaboraciones teóricas realizadas a partir de las enseñanzas amerindias. Por lo tanto, estos conceptos son fruto de un encuentro etnográfico. Según estas teorías, para los amerindios el mundo está formado de otros sujetos, más allá de los seres humanos. Cada uno de estos seres carga una vestimenta propia (tiene un cuerpo) y por consiguiente dispone de un punto de vista particular que le permite entablar relaciones entre y con los seres de múltiples naturalezas. De acuerdo con Óscar Calavia y su trabajo etnográfico con los yaminawá, habitantes de las cabeceras del río Acre en el suroeste de la región amazónica:

Es la mirada de cada uno lo que ordena el conjunto: el hombre puede ser visto como un jaguar por los pecaríes y como un pecarí por los jaguares, de modo que la condición de sujeto u objeto resulta reversible y siempre dependiente de un punto de vista (Calavia, 2005, p. 162).

Ser considerado persona y ocupar un punto de vista corresponde a una «cuestión de grado, de contexto y de posición, antes que propiedades distintivas de tal o cual especie» (Viveiros de Castro, 2010, p. 37). Por lo tanto, esta «personeidad» (Santos Granero, 2012) no aplica a todos los seres existentes, sino a aquellos que mejor encajan en el modelo de predación (predadores como el jaguar, la boa o el lagarto negro, y presas como los pecaríes, también llamados huanganas en las selvas ecuatorianas y peruanas). Como lo explica Els Lagrou a partir de su trabajo con los kawinawá, en la cuenca de los ríos Curanja, Purús y Santa Rosa, también en el suroeste de la región amazónica:

La forma en que se relacionan con la otredad implica que uno se convierte en uno mismo al convertirse parcialmente en otro, y que la subjetividad del ser se ve significativamente realzada por el contacto íntimo con, e inclusive por la incorporación del otro, ya sea un enemigo, un ser espiritual, un animal o una planta. Esta incorporación puede tomar varias formas. Las formas más espectaculares, bien conocidas en la literatura, son: comerse al enemigo, tomar las cabezas de los enemigos como trofeos, incorporar sus almas o canciones, adoptar sus hijos y robarse a sus mujeres para casarse con ellas (Lagrou, 2012, p. 260). 
La alteridad representa una condición necesaria para la existencia de la sociedad. En este sentido, «las teorías indígenas amazónicas sobre la personeidad ponen énfasis en la incorporación del Otro como un rasgo indispensable de la construcción del Yo» (Santos Granero, 2012, p. 22). El modelo predador-presa que vehicula relaciones entre seres de distintas naturalezas resulta ser «un contexto pragmático y teórico altamente favorable al perspectivismo. No hay existente que no se pueda definir en términos de su posición relativa en una escala de capacidad predatoria» (Viveiros de Castro, 2010, p. 36). Es decir que, donde los indígenas ven sangre, los jaguares ven cerveza de yuca; donde los indígenas ven un charco de lodo, las huanganas ven un lugar sagrado y ceremonial. Los seres no-humanos adoptan el punto de vista humano, dado que en algún tiempo-espacio diverso al actual lo fueron.

Nuestra propuesta pasa por aplicar y extender el modelo de socialidad predatorio en los relatos de los runa sobre sus encuentros con entidades no-humanas, confrontando estos datos etnográficos con la teoría perspectivista y las ontologías relacionales. Los kichwa de Llanchama nos dejan entrever que los seres no-humanos emplean unas técnicas de incorporación de la alteridad que son específicas, creativas y performativas. Estas se explicitan en la seducción y en el robo de personas humanas en contextos que trascienden las nociones lineales de tiempo y espacio, así como también en el establecimiento de relaciones de parentesco entre estos. Dicho de otro modo, los seres no-humanos ven a los runa como presa en este modelo de socialidad y buscan incorporarlos como marido o mujer a través de sus respectivos métodos y modos de relacionamiento. Para hacer frente a esta situación, ellos recurren al chamán, para que sea él quien intervenga en la relación construida, reconduzca y revierta los roles. En los tres relatos observamos que los puntos de vista y las agencias de los distintos seres, humanos y no-humanos, se movilizan en dimensiones temporales y espaciales diversas y simultáneas. La alteridad en estas sociedades no es confundida ni anulada; por lo contrario, es reconocida e incorporada.

\section{TIEMPOS, (IN)DIFERENCIA Y CHAMANISMO}

Los encuentros entre seres humanos y no-humanos son organizados y analizados con los marcos de referencias y nociones de tiempo de los llanchama runa. De acuerdo con Rodrigo Martínez Novo y su trabajo etnográfico con un grupo de indígenas kichwa canelos en la Amazonia de Pastaza, en Ecuador, quien a su vez 
se refugia en las ideas de Henri Bergson [1910], comprendemos el tiempo en cuanto a «las formas en que de ese tiempo se piensa y se habla para dar sentido a los hechos que involucran a una comunidad de hablantes» (Martínez, 2012, p. 112). Esto supone, de acuerdo con Nancy Munn, examinar los procesos socioculturales por los cuales la temporalidad es construida y significada. Según esta autora, el tiempo es algo que realizamos a través de nuestros actos; somos en el tiempo, y tiempo y espacio son inseparables. A pesar de que entre los pensadores europeos el tiempo ha sido considerado muchas veces de forma independiente al espacio, en nuestras experiencias las dimensiones temporales y espaciales no pueden desligarse, y ambas se combinan de modos muy diversos. En consecuencia, y desde un punto de vista antropológico, hay que analizar el tiempo en relación con las «acciones, los actores y los espacios que generan» (Munn, 1992, p. 94).

A su vez, consideramos los trabajos etnográficos de Norman Whitten Jr. (1987) y Mary-Elizabeth Reeve (1988; 1988a) con los kichwa canelos y kichwa del Curaray, respectivamente, como fundamentales para tratar la categoría de «tiempo-espacio» entre los runa. Para estos, el kunan uras es el tiempo-espacio actual que está formado a su vez por mundos y dimensiones diferentes, aunque incompletos e inestables: el kay pacha, mundo cotidiano donde se desarrolla la vida de los runa; el uku pacha, mundo subterráneo que pertenece a los seres como el Sacha Runa y la Sacha Warmi; el urai pacha, donde moran las fuerzas de la naturaleza, y el jawa pacha, donde residen los seres invisibles. Por su parte, el unai corresponde al tiempo mítico y primordial, donde no hay división de mundos ni dimensiones, sino que todos los seres se comunican y viven en un mismo tiempo-espacio común e indiferenciado. Veremos que la noción runa del tiempoespacio supera la linealidad pasado-presente-futuro y posibilita la coexistencia de los tiempos-espacios actuales y míticos donde humanos y no-humanos fabrican y tensionan los mundos que habitan.

En esta simultaneidad de tiempos-espacios cosmológicos se manifiestan los encuentros entre seres de distintas naturalezas. El unai no corresponde a un tiempo pretérito e inaccesible, sino más bien a un tiempo ubicuo y recurrente, capaz de complementar las diferencias surgidas entre las naturalezas múltiples en el kunan uras. Heriberto sitúa las relaciones de alteridad entre los seres no-humanos y los runa en el tiempo-espacio actual, que se rige por una temporalidad lineal y espacios claramente separados, pero que pueden ser transitados tanto por estas entidades, en busca de una presa humana, como por los humanos atraídos por estos: 
Antiguamente robaban a las personas. Yaku Warmi es una mujer y Yaku Runa es un hombre. Entonces ahí adentro, porque ellos viven ahí adentro de ahí salen para cualquier cosa aquí, para buscar a la persona, a robar, a comer como quieren, escuchando el delfín. El delfín es persona, antiguamente es persona. El delfín tiene dice que el cuerpo casi de un humano, así me cuentan. Entonces el delfín igual robaba a la persona. Parecía persona, venía pero se transformaba en delfín. Entonces la boa que es anaconda también se hacía persona, le llevaba. Cuando le roba le lleva adentro para ser mujer. Si es hombre le lleva para ser mujer. Si es mujer le lleva para ser marido. Le roba a la persona y le tienen adentro. Allá es otra vida de ellos. Ese es uno, del Yaku Runa, Yaku Warmi y el delfín también. Y aquí en la selva hay otro, les decimos Sacha Runa o Sacha Warmi. También antiguamente robaban a la gente, a las personas. A veces se presentaba en la selva una mujer bella, entonces al hombre le robaba. Le decía cierre el ojo un rato. Cerraba el ojo y ya estabas adentro. De ahí desaparecería. Por eso, a veces hay muchas personas que se han desaparecido, se han ido adentro. Y ahí tiene que estar el chamán pendiente ese rato que le roba para sacarle. Si demora un tiempo, ahí ya no le puedes sacar. Eso hay que hacerle rapidito para sacarle (Heriberto, en conversación con el autor, 24/4/2019).

En el kunan uras, los seres diferenciados habitan un territorio propio donde se reconocen como «personas humanas», diseñado según sus puntos de vista particulares. De esto surge que haya seres que vivan debajo de la tierra, en el $u k u$ pacha, como el Sacha Runa o la Sacha Warmi, pero también hay un mundo que se encuentra bajo los ríos y lagunas donde vive el Yaku Runa y la Yaku Warmi, quienes según los kichwa de Llanchama los ven a ellos como papagayos volando acá arriba (navegando los ríos o pescando en la laguna).

En el tiempo-espacio actual puede suceder que los distintos espíritus-animales salgan de sus respectivos mundos y se dirijan hacia el kay pacha, lugar donde habitan los seres humanos. Para ello es necesario atravesar túneles y tomar la apariencia de un cuerpo animal, dejando ver que este tipo de ser tiene la posibilidad de realizar una metamorfosis y desde ahí establecer relaciones específicas con los runa. Estos se encontraban realizando actividades que cotidianamente suelen hacer en un día cualquiera en la comunidad, como lavar la ropa o los trastes a orillas del río, o ir de cacería al monte, solo que aquí las entidades no-humanas han buscado los modos de agenciarlos, es decir, de seducirlos, de llevarlos consigo hacia a sus propios mundos e incorporarlos como marido o mujer. Así lo cuenta Brígida, que introduce el elemento del sueño como un nuevo tiempo-espacio onírico, donde el Yaku Runa actúa sobre ella: 
Sí, me ha sucedido a mí, en el río, el Yaku Runa que dice la boa. Yo, como no tenía agua en Nuevo Rocafuerte, bajaba sola al río a lavar la ropa, a lavar los trastes, todo ya. No tenía agua para nada en la casa. Yo bajaba y me daba sueño, que rico sueño, ganas de acostarme en el muelle a dormirme [...] Y soñaba en la noche un hombre simpático, zambito, pero propio negro, brillosito. Así soñaba. Y cuando una vez vino mi mami a mi casa a visitarme, digo mami qué será que sueño todas las noches, negrito simpático que me sigue, que me quiere llevar, me jala al río. Como yo tenía el pelo largo aquí, bien largo aquí, y me decía mi mami, dice te va a robar la boa, ese es mal sueño, te está siguiendo el animal del río, el Yaku Runa me dice (Brígida, en conversación con el autor, 29/04/2019).

Una situación similar es la que nos narra Cristian cuando reconoce que la selva quiso apoderarse de él, primero confundiéndolo en el monte provocando que se perdiera, y luego por medio de alucinaciones que no lo dejaban dormir.

Yo esa noche no pude dormir. Ya como que me estaba queriendo llevar la selva. Miraba a los animales, todos tipos de animales, miraba así... visión. Había mujeres que me llamaban, vamos, de ganas escuchaba aquí. Quería dormir, el ruido de los chanchos, ese ruido me venía, de la huangana. Miraba a los animales ahí comiendo. De mi cama me miraban, les miraba a los animales. Le digo mami, ¿no escuchan, digo? ¿Miran lo que yo veo, digo? Cogí una linterna, mira ahí está la tortuga, digo, encima de mí venían los monos. Mi mamá no, hijo, tú estás mal dijo, hay que hacerte ver con el chamán. Fueron a ver mi tío Ángel. Él me vio, uta, dice mi tío, si te quedabas dos, tres días más ya no aparecías dice, te ibas al inframundo (Cristian, en conversación con el autor, 10/5/2019).

Con respecto a la historia del antepasado Pillán, esta es diversa a las dos situaciones de vida cotidiana que hemos descrito. El runa transitaba y era capaz de mantener su vida en ambos mundos, kay pacha y uku pacha, pero solo hasta cierto punto, momento en que es incorporado definitivamente por la mujerespíritu-animal y la selva como entidad viviente.

La historia de Pillancocha es con la persona que se llamaba Pillán. El apellido de él es Huatatoca, entonces tío de mi abuelita. Ellos vivían en el sector que hoy en día le llamamos Pillán. Entonces él se mantuvo ahí algunos años de vida con su familia. Él salía a cazar. Hay días que él madrugaba y días que no madrugaba, entonces este señor se iba a cazar y volvía a los primeros días. Iba y volvía. Iba y volvía. Pero ya así a la larga este señor iba quedándose, como que se perdía en el monte. Iba quedando cuando iba solo un día, dos días y no aparecía. Entonces así ya total es que como por cuarta vez que se va, va llevándose al hijo llamado Apolinario. Entonces este Apolinario lo que hace es 
descubrir. Dice que el papá ha llegado allá y que nosotros no estuvimos perdidos, sino que el papá tiene otra esposa que es parecida a usted, le dice a la mamá. Entonces, cuando ellos se metían a esos túneles estaba esa otra mamá. Entonces dice a él cuando le cogía como espíritu le llevaba. Le abrazaba, dice que le decía cierre los ojos, como que le abría la puerta y sonaba cuando él abría los ojos ya estaba dentro de ese túnel. Y cuando llegaba él no perdía la memoria. A la llegada dice que los perros ladraban, los perros dice que era el tigre. Así es que él observaba para poder sentar, ¿en qué se van a sentar? Y le traían, dice, esa tortuga y le ponían ahí, ese era como un taburete que se debía sentar ahí. Y así es que él se mantuvo ahí como tres días y acompañándose con los hermanos que para nosotros le llamamos diabla, era ese igualito a la mamá (Andrés, en conversación con el autor, 13/05/2019).

La indiferenciación es la madre de todas las diferenciaciones, dicho de otro modo, de la indiferencia emerge la diferencia. En los tiempos míticos y primordiales, los seres tienen apariencias similares, pueden comunicarse entre sí y habitan entre todos en un solo mundo de manera armoniosa (Whitten 1987; Reeve 1988a). En los tiempos actuales la situación es diversa, ya que los nacientes seres diferenciados viven en sus respectivos mundos y, si bien se ven a sí mismos como personas, ven a los demás bajo un modelo creativo y performativo de predadores y presas. El kunan uras y el unai se entrelazan conformado un rizoma de relaciones continuas entre los seres de múltiples naturalezas. En esta intersección temporal-espacial es donde se movilizan y despliegan los distintos modos de establecer relaciones y de incorporar a la alteridad según sea la naturaleza del ser que tiene el punto de vista.

Observamos en estos casos que el runa es visto como presa y susceptible de ser incorporado por los seres no-humanos. En el kunan uras surgen las diferencias entre los ya diferentes seres que no pueden resolverse en la dimensión en la que emergen, por lo que es necesario que intervenga el chamán. Para ello accede al unai, donde las diferencias se reducen y se vuelven accesibles, siendo posible, como no, agenciar y reconducir las relaciones iniciales. Después vuelve al kunan uras y les comunica lo que ha sucedido, recomendándoles adoptar ciertos comportamientos para así evitar un nuevo reencuentro con estos seres. El kunan uras y el unai coexisten simultáneamente entrelazados. Así, solo el chamán puede mantener su punto de vista y comunicar con los otros, enfrentar, actuar y agenciar a sus pares humanos y no-humanos y su entorno. Es en este tiempo-espacio, en el unai, donde el chamán resuelve y vehicula una salida a la relación de predador-presa suscitada en el tiempo-espacio diferenciado. 
Según estos relatos, en el kunan uras los seres no-humanos buscan atraer y seducir al runa para luego, a través de la técnica del robo, incorporarlo y llevarlo consigo hacia su respectivo mundo para hacerlo marido o mujer. En el caso de Brígida, ella experimenta dos situaciones. Por las mañanas, mientras se encontraba lavando a orillas del río en su pequeño puerto, unas ganas de dormir le vienen mientras escucha a su hija pequeña llorar en casa. La otra situación ocurre por las noches mientras duerme, donde recurrentemente sueña con un hombre de piel negra que se la quiere llevar. Ella le comenta a su madre, quien le dice que tiene un «mal sueño, que la está siguiendo el animal del río, el Yaku Runa.

Por su parte Cristian, quien ha decidido ir solo de cacería, se ha perdido en el monte. Con su machete y un arma con cartuchos de su tío Heriberto, camina en el interior de la selva encontrándose con pantanos, aguas negras y anacondas. Logra saber estar en ella, es decir, en qué aguas nadar, ubicarse a partir de la salida del sol, en qué árbol refugiarse por la noche o qué raíces comer, y volver a la comunidad después de tres días de estar perdido. Al llegar la noche, no puede dormir. Ve animales dentro de su casa, los escucha, están ahí con él. Los percibe, los siente. Su madre le dice: «Tú estás mal, hay que hacerte ver con el chamán». Los espíritus, los animales y la selva misma son entidades con agencias que como tales buscan la incorporación de la alteridad humana. Para ello, despliegan unos modos de relacionamiento en tiempos-espacios diversos, en efecto, tanto en el kunan uras como en el unai. Este encuentro ocurre en el monte y a orillas del río, pero también en los sueños y en las alucinaciones. El sueño es otro tiempoespacio donde el runa es atraído por los seres no-humanos, y donde el chamán puede conocer la diferencia y sus perspectivas. Como plantea la antropóloga Tania Stolze Lima:

Allí, el animal (y otras categorías ontológicas), bajo ciertas condiciones, se transforma en un ser humano para otra persona; es identificado como persona por otra persona, y las dos forman (o no) una alianza más o menos duradera (es decir, una que se puede experimentar en diferentes noches de sueño) (Stolze Lima, 1996, p. 28, traducción propia).

El sueño es un entrelazamiento entre el unai con en el kunan uras, «es un modo de relación con los interlocutores oníricos que pertenecen al mundo de los muertos, al de los espíritus y al mundo de los vivos que dormitan» (Bilhaut, 2011, p. 50). Es un viaje a los tiempos-espacios donde la diferencia es reducida, permitiendo al chamán y a los seres espirituales-animales, aunque diversos en sus naturalezas, agenciar sobre el «otro», comunicando e intercambiando sus 
puntos de vista y los modos en qué se establecen las relaciones de alteridad. Es en el sueño donde convergen el tiempo primordial y el tiempo actual, y donde las distintas naturalezas se vuelven accesibles para los chamanes, quienes pueden intervenir sobre ellas. Tal como afirma Eduardo Viveiros de Castro, el chamanismo amazónico puede definirse como:

La habilidad que manifiestan algunos individuos para atravesar las barreras corporales entre las especies y adoptar la perspectiva de subjetividades específicas, de manera de administrar las relaciones entre estas y los humanos. Al ver a los seres no humanos tal como se ven ellos mismos (como humanos), los chamanes son capaces de asumir el papel de interlocutores activos en el diálogo transespecífico; y sobre todo, son capaces de volver para contar el cuento, cosa que los profanos difícilmente pueden hacer. El encuentro o el intercambio de perspectivas es un proce.so peligroso, y un arte político, una diplomacia (Viveiros de Castro, 2010, p. 40).

Son las relaciones iniciadas en el tiempo-espacio actual y diferenciado, las que el chamán busca agenciar para revertir la perspectiva y liberar al runa de una posible incorporación al mundo no-humano. Para ello se traslada al espaciotiempo primordial, acortando la distancia entre sí y el otro, de manera que pueda regenerar la diferencia y devolver al runa a su rol cotidiano como cazador y no presa, como esposa y no robada. En este sentido, coincidimos con el planteamiento de la antropóloga Els Lagrou cuando afirma que «un ser se apropia no tanto al domesticar las fuerzas salvajes de la otredad, sino más al disminuir gradualmente la distancia entre sí y el otro, en términos espaciales, cognitivos y corporales» (Lagrou, 2012, p. 261).

El Yaku Runa, las mujeres-espíritus-animales y la selva en sí misma son sujetos con agencias que establecieron relaciones de alteridad con los runa a través de la seducción, con el propósito de incorporarlos definitivamente a sus respectivos mundos diferenciados. En cada una de estas relaciones ofició de interlocutor entre las múltiples naturalezas el chamán a través de los sueños y de la toma de ayahuasca, cuyo poder le permitió acceder al tiempo-espacio primordial donde pudo transformar y redirigir las relaciones iniciales. De este modo se conoce la diferencia y lo que es más importante, se actúa sobre ella y se revierte la relación predador-presa: «Conocer es personificar, tomar el punto de vista de aquellos que deben ser conocidos. La forma del Otro es la persona» (Viveiros de Castro, 2004, p. 43). Estas relaciones de alteridad son desplegadas en las temporalidades-espacialidades runa que hemos explicado, donde el kunan uras se actualiza recurriendo al unai. Ser persona no es solo un atributo de hombres y 
mujeres, sino también de algunos animales, espíritus y plantas, siendo las relaciones con la alteridad entre múltiples naturalezas las que sostienen el universo ontológico runa, la composición que hacen de lo social y los modos específicos de habitar la selva.

El animal del río, el Yaku Runa o la boa corresponden a un mismo ser no-humano en el relato de Brígida. Ella ha pensado que por estar bien casada jamás iba a tener un encuentro con este espíritu-animal. Su madre le comenta que mantener un vínculo matrimonial e hijos no es razón para que el Yaku Runa no quiera robarla. Es decir, que el hecho de estar casado ante un dios, que es al mismo tiempo runa y cristiano como lo es Pachayaya para los llanchama runa, no se traduce en que los espíritus de la selva no busquen fabricar una relación de alteridad e invitarlos a vivir con ellos en sus respectivos mundos. Por otro lado, se enfatiza en el hecho de que si eres mujer y tienes el cabello largo, eres una sujeta susceptible de ser atraída y seducida por el Yaku Runa, de ser robada por la boa. La seducción y el robo de hombres y mujeres es el modo particular que los seres no-humanos disponen para establecer relaciones de parentesco con los Runa, y según sea el caso, ser incorporado como marido o mujer, siendo posible solo relaciones heterosexuales entre estos.

Bueno, esa vez llegó un compadre que sabía, era curandero. Él bajó al río en la tarde, como a las cinco y media. Una tremenda cabezota de boa, en la orillita adonde que yo tenía el muelle. Dice que lloraba como tiernito, guagua tierna. Lloraba. Él subió del río asustado, me dice comadre aquí en este puerto veo mal me dice. ¿Qué será le digo? Una tremenda cabeza de boa, le digo es que está mal su puerto. Yo quiero yagé, dijo. ¿Dónde puedo conseguir? Y conseguimos al otro lado, mi papá tenía. Cocinamos todo y a las diez de la noche empezó a tomar esa droga. Mi compadre me dijo ahora si ya se libra comadre, ya no se va a perder en el río. Le voy a matarle con un trueno dijo, como él es curandero, de un buen trueno le maté dijo. Ya no la ha de venir a molestar más. Entonces yo ya me ni sueño ni nada. Le dejó completo. Mi compadre me dijo que ha sido ya usted así de perderse en el río, con su guagüita en la hamaca llorando. Mi compadre también se quedaba botado. Yo dos días, tres días máximo, dice, yo ya me perdía en el río lavando la ropa. Eso me sucedió a mí y me pegué un susto y me corté el pelo. Desde ahí vivo pelo mocho. Porque dicen que a los que tienen el pelo largo persigue la boa, me hicieron asustar. Hasta ahora vivo pelo corto (Brígida, en conversación con el autor, 29/4/2019).

Esta noción del robo es un conocimiento práctico expandido entres los kichwa amazónicos. Ellos lo saben y lo enfrentan, acudiendo a aquellos que sí 
tienen la capacidad y el poder de comunicar con estos seres. Es en este contexto donde interviene el chamán, cuya relación con Brígida es de compadrazgo. Él se acerca al puerto y tiene una mala visión. Visualiza una pequeña cabeza de boa que llora y llora. Con esta información primaria, el chamán solicita de la planta de ayahuasca para acceder a un tiempo-espacio que le permita agenciar las relaciones entre Brígida y el animal del río. Una vez en el unai, el chamán hace un trueno y acaba con el espíritu-animal corporalizado en boa. Lo ha vencido en el viaje que ha realizado durante la noche hacia aquel tiempo-espacio, luego de la ingesta de yagé (ayahuasca en lengua kichwa). El trueno tuvo lugar en el espacio-tiempo del sueño, en contacto con el unai, pero su consecuencia trasciende, repercutiendo en el kunan uras y redirigiendo las relaciones entre los seres humanos y no-humanos. Además, le indica que debe cortarse el pelo, ya que es una estrategia para evitar que el Yaku Runa intente robarla nuevamente.

En el caso de la alucinación de Cristian, pareciera que la selva se ha trasladado a su propia habitación como un agente que lo busca para sí. Es al mismo tiempo observador y observado por mujeres que lo reclaman y animales del monte que comen a los pies de su cama. No puede dormir, continua en su alucinación. Ante esto su madre recurre al chaman, quién es el tío abuelo de Cristian (hermano menor de su abuela paterna). Si bien el runa interpreta el hecho de perderse en la selva como una prueba que le ha puesto Dios debido a su conducta y trato con sus padres, esta concepción y modo de significar la situación vivida es atravesada por la lectura e intervención que hace el chamán, quien realiza una limpia, lo soba y lo baña. Luego le indica unas condiciones que debe cumplir responsablemente para alejar a aquellos seres no-humanos que han querido llevarlo. Estas incluyen no beber licor ni fumar, además de una dieta sin sal durante el periodo de un año. Para cumplirlas, Cristian decide salir de la comunidad de Llanchama y dirigirse a Nuevo Rocafuerte junto a su madre. Transcurridos diez meses desde que se perdió en la selva, vuelve a beber alcohol en una fiesta familiar. Ante esto, el chamán viaja al poblado y le indica que debe volver a Llanchama para concluir los últimos dos meses. Además, le manifiesta que le han hecho «maldad»para que se pierda en el monte y le vuelve a indicar qué es lo que debe realizar para neutralizar a los espíritus y así poder continuar habitando la selva sin la amenaza de ser llevado.

De ahí pasó los dos meses, me puso a prueba a cambio él, mi tío, el chamán. Toma me dice, llévate este retro y un machetito de este tamaño. Ándate. No tengas miedo. Me fui por el mismo lugar que me perdí. Reconoce dónde te fuiste dice. Me fui. Ahí miraba los animales, los animales mansitos venían 
así, monos, las aves, las pavas, y les cogí. Les disparaba. Y en la tarde que pasó ya, llego, mira, de suerte, digo, traje cacería. Ellas querían llevarte decía, la gente que dicen les mataste, a las aves que mataste, esas eran las mujeres que te querían llevar. Así me dijo. Me dijo que me iba a quedar como bueno en cacería. Recién hace unos cuatro días me encontré. Me dijo que tenga cuidado, que me está siguiendo de nuevo la mala gente. Así me supo decir mi tío, por eso ese día que me fui con René, le dije vamos. No ande solo, me dijo, acompañado, me dijo. Por eso andaba ahora entre dos. Antes andaba solo (Cristian, en conversación con el autor, 10/5/2019).

La lectura que hacen los chamanes de las situaciones vividas por Brígida y Cristian es que, si no se actuaba expeditamente, estos iban a ser incorporados por la selva y los seres no-humanos. Así, en un plazo de pocos días serían devorados por el tigre o por la boa. Para redirigir esta relación de alteridad es que los chamanes buscan comprender la diferencia, interactuando con las entidades no-humanas y ejerciendo su agencia. Porque su ingreso en el tiempo primordial y mítico les permite comunicarse con estos seres, y al comprender otras perspectivas, pueden ejercer su saber-poder sobre ellas. Si los ven, los pueden simbolizar. Para ello se viaja al unai desde el kunan uras. Es en este tiempo-espacio donde logra alejar al Yaku Runa a través de un trueno. Acción seguida, Brígida se corta el cabello y desde entonces no ha vuelto a tener un mal sueño ni se ha reencontrado nuevamente con el animal del río.

Por su parte, Cristian, una vez que concluyó el año de condiciones que el chamán le impuso, este lo vuelve a poner a prueba. Le entrega herramientas para la cacería y lo envía solitariamente al mismo lugar donde se había perdido hace un año. Lo hace volver y reconocer. Una vez en el lugar se detiene un momento, los animales se le acercan y este caza unas pavas. Al retornar y encontrarse con su tío abuelo, este le comenta que esas eran las mujeres en cuerpos de aves que habían querido robarle, y que luego de toda esta experiencia con la selva y los seres no-humanos va a quedar como bueno en cacería. Ha sido el chamán quien en definitiva ha redirigido las relaciones iniciales en la que Cristian se había convertido en presa para las mujeres y la selva, revirtiendo las agencias e incorporando a la alteridad no-humana. Finalmente le advierte que ha tenido un sueño reciente donde ha visto nuevamente que le están haciendo maldad, que debe andar con cuidado cuando vaya al monte. Por esta razón le ha solicitado a René, su primo, para que lo acompañe en las últimas vueltas, considerando así la palabra del chamán y la ética runa para afrontar las relaciones con la alteridad que puedan establecerse en los tiempos actuales. 
En la historia de Pillán, en cambio, la situación es diversa. Esto ya que el antepasado de los kichwa de Llanchama estableció una relación de parentesco con una mujer-espíritu-animal y tuvo hijos con esta, a los cuales visitaba en un mundo diferente del mundo en el que vivía junto a su familia runa. Para llegar donde habitaba su familia no-humana, lo hacía a través de túneles que lo conducían hacia interior de la selva. Pillán se movilizaba entre estos mundos diferenciados del kunan uras, iba y venía entre el kay pacha y el $u k u$ pacha, por lo que el «parentesco no solo fluye de una persona a otra, sino también entre el mundo natural y las gentes, e igualmente entre los seres de tiempos míticos y del presente» (Uzendoski, 2006, p. 164). En el mundo donde vive su mujer espíritu-animal, nombrada como diabla por los runa, también se bebe la chicha, los tigres son perros y las tortugas son asientos (en concordancia como narra Heriberto en el relato sobre cómo viven el Sacha Runa y la Sacha Warmi en sus respectivos mundos).

Los chamanes, advertidos de la situación del runa que solía perderse primero algunos días y luego ya semanas, intentaron mediar, sin embargo no pudieron agenciar en las relaciones establecidas entre ellos. Pillán fue incorporado paulatinamente por la diabla y por la selva a través del establecimiento de relaciones de parentesco. Luego de muchos viajes hacia el mundo interior, hubo uno del cual no regresó más al mundo de los runa. Mis interlocutores suelen decir que Pillán no ha muerto, sino que vive en las cercanías a una laguna que lleva su nombre y que hace referencia al lugar donde acostumbraba a perderse. Pillán fue «endiablado», la mujer no-humana y la selva se lo llevaron y hoy vive en el interior de ella en uno de los mundos diferenciados del kunan uras. Goza de una temporalidad primordial e indiferenciada que se expresa en el hecho de que continúa manifestándose ante la gente de la ribera a través de gritos, fuertes lluvias y truenos cuando estos se van de pesca en la laguna, siendo un lugar que poco a poco han ido reconociendo, accediendo e incorporando en los últimos treinta años. 
Cuadro 1. Esquema de las relaciones de alteridad entre no-humanos y los llanchama runa en los distintos tiempos-espacios cosmológicos mediados por el chamán

\begin{tabular}{lllll}
\hline NO-HUMANO & HUMANO & $\begin{array}{l}\text { TIEMPO/ESPACIO } \\
\text { (cruce de perspectivas) }\end{array}$ & $\begin{array}{l}\text { INTERVENCIÓN } \\
\text { CHAMÁNICA }\end{array}$ & RESOLUCIÓN \\
\hline $\begin{array}{l}\text { Yaku Runa; } \\
\text { boa }\end{array}$ & Brígida & Río; sueños & $\begin{array}{l}\text { Toma de Yagé; } \\
\text { trueno }\end{array}$ & $\begin{array}{l}\text { Corte de pelo; dejó } \\
\text { de ser agenciada }\end{array}$ \\
$\begin{array}{l}\text { Mujeres/pavas; } \\
\text { la selva }\end{array}$ & Cristian & $\begin{array}{l}\text { Monte; } \\
\text { alucinación }\end{array}$ & $\begin{array}{l}\text { Limpia; dieta; } \\
\text { volver al monte }\end{array}$ & $\begin{array}{l}\text { Bueno en cacería; } \\
\text { andar acompañado }\end{array}$ \\
$\begin{array}{l}\text { Mujer/diabla; } \\
\text { la selva }\end{array}$ & Pillán & $\begin{array}{l}\text { Monte; túneles; } \\
\text { inframundo }\end{array}$ & Aventar & $\begin{array}{l}\text { Se hizo marido; se } \\
\text { volvió selva (laguna) }\end{array}$ \\
\hline
\end{tabular}

\section{ENTRE HUMANOS Y NO-HUMANOS, MÁS ALLÁ DE ACTUAL Y PRIMORDIAL}

Hemos explicado que son intensas relaciones «flexibles y dinámicas» (Magnoni, 2018, p. 104) entre los distintos seres existentes las que constituyen la socialidad amazónica, organizándose bajo un modelo predatorio, que en el caso de los runa se vuelve creativo y performativo. Inicialmente, los seres no-humanos proponen la incorporación de la alteridad humana a través de la seducción, el robo y el establecimiento de relaciones de parentesco. En este modelo de socialidad el runa es visto como presa por las entidades espirituales-animales, quienes los agencian para que adopten sus puntos de vistas, se dirijan a vivir con ellos a sus mundos y se conviertan en sus esposas o maridos. En términos runa: el kay pacha sería el mundo habitado por los runa en el kunan uras, mientras que los seres no-humanos con capacidad de metamorfosis habitan en sus respectivos «otros» mundos, también en el tiempo actual, gozando eso sí, de una temporalidad intemporal propia del unai. De modo que ambos tiempos-espacios se entrecruzan, no son estancos, sino que se comunican entre sí a través de túneles, fisuras oníricas o alucinaciones. Estas fisuras son aprovechadas por los seres no-humanos para atraer a los humanos a sus mundos. Seguido el chamán debe intervenir, ya que también posee la capacidad para transitar entre estos distintos tiempos-espacios con el propósito de resolver las indiferenciaciones iniciales que permitan mantener los mundos diferenciados en el kunan uras. En suma, el kay pacha se sostiene como un lugar diferenciado en el tiempo-espacio actual y debe ser mantenido con tenacidad, ya que es constantemente puesto a prueba por seres no-humanos, quienes recurren al tiempo-espacio primordial e indiferenciado para agenciar sobre los humanos. 
La selva para los runa es vista como una entidad animada y habitada por seres de múltiples naturalezas que se movilizan en distintas temporalidadesespacialidades, donde lo primordial se sitúa como un tiempo-espacio ubicuo para ellos, trascendiendo así cualquier orden temporal lineal. Sin embargo, algunos seres pueden transitar entre uno y otro, con más o menos fortuna. El chamán puede actuar sobre el no-humano y, si es hábil, revertir relaciones indeseadas. Por su capacidad de trasladarse hacia el tiempo-espacio primordial, ya sea a través del sueño o de la ingesta de ayahuasca, puede comunicarse con estos seres y actuar sobre el tiempo-espacio actual. En este sentido vemos que «como otros movimientos milenarios del mundo, la gente de Napo sigue usando elementos religiosos de su cosmovisión para transformar el presente» (Uzendoski 2006, p. 169). Así, kunan uras y unai «coexisten simultáneamente en el presente en forma no lineal y se encuentran ubicados en los sistemas de conocimiento de los runa contemporáneos» (Whitten, 1988, p. 92). Estos sistemas cosmológicos acerca de la coexistencia de tiempos-espacios míticos y actuales les permiten a los llanchama runa reconocerse e identificarse, junto a los demás seres y entidades, como habitantes desde tiempos inmemoriales de la Amazonia. De acuerdo con Delfina Magnoni, los napo runa poseen una «virtud transformacional que concibe el cambio, la mezcla y la incorporación como parte fundamental del seguir siendo» (Magnoni, 2018, p. 104). Este cruce de perspectivas y conocimiento de la alteridad posibilitan fabricar unas narrativas propias respecto a los modos de existencia runa. Todos estos elementos cosmológicos deben tratarse de modo relacional con aquellos conocimientos que se tienen sobre su propia historia y que se encuentran contenidas en las memorias de los mayores de la comunidad, además de su lengua madre, el kichwa amazónico, procurando ser enseñados y transmitidos a través de agentes vehiculadores hacia las nuevas generaciones. Solo un pueblo que conoce su historia, que habla su lengua y que ve en la multiplicidad de naturalezas un modo orgánico de habitar el territorio tiene el poder de transformar su realidad, construir su presente y albergar su futuro.

Por último, enfatizar que nuestra pretensión ha sido aquí describir la vida social de los kichwa de Llanchama a partir de su concepción temporal-espacial y su relación con la alteridad, pero asumimos por entero que solo hemos esbozado en estas líneas una clave interpretativa de su rico y complejo universo. Su cosmología y modos de habitar la selva junto a otros seres exceden lo que hemos sido capaz de escribir en estas páginas. Así, los conceptos antropológicos desarrollados bajo el paraguas teórico del giro ontológico nos han servido de ayuda para expandir horizontes de posibilidad y de significar los universos y los 
sujetos entre quienes es posible establecer relaciones en el mundo que se habita y en qué temporalidades estas agencias pueden movilizarse. En estos términos, las categorías analíticas y las interpretaciones aquí ofrecidas no clausurarían ni cosificarían las formas de pensarse en/con el territorio y de habitar junto los demás seres, sino más bien abrirían un abanico de relaciones entrelazadas y continúas en tiempos-espacios coexistentes y simultáneos. Una «nueva» forma de pensar la articulación entre tiempos, espacios, agencias y actores. La autoridad epistemológica última radica siempre en sus vivencias y relatos, en Brígida, Heriberto, Cristian, Andrés, Pillán... en los llanchama runa que habitan en el Tiputini. Son ellos y ellas quienes nos ayudan a hacer una antropología abierta e inconclusa y sus respectivas narrativas compartidas son nuestras enseñanzas que nos ayudan a comprender de mejor manera nuestra condición humana.

\section{Agradecimientos}

A los llanchama runa por compartir conmigo sus conocimientos y permitirme practicar el oficio de antropólogo. A Emily Carraro por su presencia, labor y apoyo en el trabajo de campo. Y a Elisenda Ardèvol por aquella comunicación siempre directa, frontal y transparente, y por sus comentarios en la formulación y redacción de este artículo.

\section{REFERENCIAS}

Bilhaut, Anne-Gaël (2011). El sueño de los záparas. Patrimonio onirico de un pueblo de la Alta Amazonía. Quito: Abya-Yala.

Cabodevilla, Miguel Ángel (2007). Coca. La región y sus historias. Quito: CICAME.

Calavia, Óscar (2005). El rastro de los pecaríes. Variaciones míticas, variaciones cosmológicas e identidades étnicas en la etnología pano. Journal de la société des américanistes (87), 161-176. https://doi.org/10.4000/jsa.1846

Descola, Philippe (2004). Las cosmologías indígenas de la Amazonia. En Alexandre Surrallés y Pedro García (eds.), Tierra adentro: territorio indígena y percepción del entorno (pp. 25-36). Copenhague: IWGIA documento n. ${ }^{\circ} 39$.

Descola, Philippe (2012). Más allá de naturaleza y cultura. Buenos Aires: Amorrortu.

Fausto, Carlos y Michael Heckenberger(eds.)(2007). Introduction. En Time andmemoryin indigenous Amazonia (pp. 1-46). Gainesville: University Press of Florida. 
Hudelson, John (1987). La cultura quichua de transición. Su expansión y desarrollo en el Alto Amazonas. Quito: Abya-Yala y Banco Central del Ecuador.

Kohn, Eduardo (2013). How forest think? Toward an anthropology beyond the human. Berkeley: University of California Press. https://doi.org/10.1525/califor$\mathrm{nia} / 9780520276109.001 .0001$

Lagrou, Els (2012). La memoria cristalizada de los artefactos: una reflexión sobre la agencia y la alteridad en la construcción de imágenes entre los Cashinahua. En Fernando Santos Granero (ed.), La vida oculta de las cosas. Teorías indígenas de la materialidad y la personeidad (pp. 255-282). Quito: Smithsonian Tropical Research Institute y Abya-Yala.

Macdonald, Theodore (1997). De cazadores a ganaderos. Quito: Abya-Yala

Magnoni, Delfina (2018). Análisis etnohistórico de las resistencias y transformaciones de los Napo Runa. TRIM, 15, 89-106.

Martínez, Rodrigo (2012). Del tiempo insostenible y del sentido del tiempo en las comunidades kichwa canelos. Desacatos, 40, 111-126. https://doi.org/10.29340/40.259

Medrano, Celeste y Florencia Tola (2016). Cuando humanos y no-humanos componen el pasado. Ontohistoria en el Chaco. AVÁ, 29, 99-129. Recuperado de https:// www.ava.unam.edu.ar/images/29/n29a04.pdf

Munn, Nancy (1992). The cultural anthropology of time: A critical essay. Annual Review of Anthropology, 21(1), 93-123. https://doi.org/10.1146/annurev. an.21.100192.000521

Muratorio, Blanca (1998). Rucuyaya Alonso y la historia social y económica del Napo. 1850-1950. Quito: Abya-Yala.

Oberem, Udo(1980). Los Quijos: historia dela transculturación de ungrupoindígenaenel Oriente ecuatoriano. Otavalo: Instituto Otavaleño de Antropología.

Reeve, Mary Elizabeth (1988). Cauchu Uras: Lowland Quichua Histories of the Amazon Rubber Boom. En Jonathan Hill (ed.), Rethinking History and Myth: Indigenous South American Perspectives on the Past (pp. 19-34). Urbana: University of Illinois Press.

Reeve, Mary Elizabeth (1988a). Los Quichua del Curaray. El proceso de formación de la identidad. Quito: Abya-Yala y Banco Central del Ecuador.

Rival, Laura (2004). El crecimiento de las familias y los árboles: la percepción del bosque de los huaorani. En Alexandre Surrallés y Pedro García (eds.), Tierra adentro: territorio indígena y percepción del entorno (pp. 97-120). Copenhague: IWGIA documento n. ${ }^{\circ} 39$. 
Santos Granero, Fernando (ed.) (2012). Introducción. En La vida oculta de las cosas. Teorías indigenas de la materialidad y la personeidad (pp. 13-54). Quito: Smithsonian Tropical Research Institute y Abya-Yala.

Stolze Lima, Tânia (1996). O dois e seu múltiplo: réflexões sobre o perspectivismo em uma cosmología tupi. Mana, 2(2), 21-47. https://doi.org/10.1590/S010493131996000200002

Surrallés, Alexandre (2002). De la percepción en antropología. Algunas reflexiones sobre la noción de persona desde los estudios amazónicos. Indiana, 19-20, 59-72. https://doi.org/10.18441/ind.v19i0.59-72

Tola, Florencia. (2019). No-humanos que hacen la historia, el entorno y el cuerpo en el Chaco argentino. Etnográfica, 23(2), 489-513. https://doi.org/10.4000/etnografica. 6913

Uzendoski, Michael (2006). El regreso de Jumandy: historicidad, parentesco y lenguaje en Napo. Íconos (26) 161-172. https://doi.org/10.17141/iconos.26.2006.180

Uzendoski, Michael (2010). Los Napo Runa de la Amazonía ecuatoriana. Quito: Abya-Yala.

Viveiros de Castro, Eduardo (1996). Os pronomes cosmológicos e o perspectivismo ameríndio. Mana, 2(2), 115-144. https://doi.org/10.1590/S010493131996000200005

Viveiros de Castro, Eduardo (2004). Perspectivismo y multinaturalismo en la América indígena. En Alexandre Surrallés y Pedro García (eds.), Tierra adentro: territorio indígena y percepción del entorno, editado por Alexandre (pp. 37-79). Copenhague: IWGIA documento n. ${ }^{\circ} 39$.

Viveiros de Castro, Eduardo (2010). Metafisicas caníbales. Líneas de antropología postestructural. Madrid: Katz.

Whitten Jr, Norman E. (1987). Sacha Runa: etnicidad y adaptación de los quichuas hablantes de la Amazonia ecuatoriana. Quito: Abya-Yala. 